\title{
'Kill Venice': a systems thinking conceptualisation of urban life, economy, and resilience in tourist cities
}

\author{
Silvio Cristiano (iD ${ }^{1 \times} \&$ Francesco Gonella ${ }^{1}$
}

\begin{abstract}
Mass tourism has been creating increasing complaints and resistances in many tourist cities worldwide. The global Covid-19 health emergency has further affected the complex relationship between the activities of city dwellers and those of the tourist flows. Be the visitors present or abruptly absent, the effects of tourism on housing, labour, and the urban economy as a whole can threaten the very survival of a tourist destination. The ultimate goals of tourist-based transformations are not clear, nor their relationship with the resilience of destinations. A systemic perspective is here offered on tourism in cities, with a focus on the city that likely exhibits the highest level of tourist attraction with respect to its vulnerability, that is, Venice, Italy. Various aspects of its sustainability and resilience, along with the involved interconnection and dependency links, are taken into consideration. Currently proposed alternative scenarios are presented, and their weaknesses commented. Some implications are also addressed for sustainable and resilient transformations. The comprehension of the dynamics that drive a tourist city system, together with the study of its systemic leverage points, appear to be mandatory for effective urban policies and planning.
\end{abstract}

\footnotetext{
${ }^{1}$ Università Ca' Foscari Venezia, Venice, Italy. ${ }^{\varpi_{e}}$ email: silvio.cristiano@unive.it
} 


\section{Introduction}

fter tourism started to be addressed as a controversial trend, controversial formulas appeared in international agendas, such as for example the concept of "sustainable tourism." These are frequently used just for labelling operations, thus becoming very little credible in a lasting perspective of socioeconomic and ecological sustainability. International organisations and scholars debate about the goodness of sustainable paradigms for tourism and development (see for instance Butler, 1999; UNWTO, 2020), sometimes claiming the possibility of minimum impacts from tourism while conserving a destination's "authenticity" (see UNWTO, 1993; UNEP, 2005; Beech et al., 2006; ICOSMOS Documentation Centre, 2017). In this paper, we do not consider nature-based forms of tourism (Force et al., 2018; Honjo and Kubo, 2020), nor community-based ones (see for instance Leposa, 2020), since the debate about mass tourism and economic fragility is concerned with the largely prevailing form of modern tourism as described below. The acceleration of material and immaterial transformations to increase the accommodation capacity and location branding is causing conflicts in many mass tourist destinations. Against what is often defined as overtourism (Dodds and Butler, 2019; Milano et al., 2019; Perkumiené and Pranskūnienè, 2019; Seraphin et al., 2018), forms of resistance have been reported worldwide: from Oceania and South-Eastern Asia (Kerr and Wardana, 2019; Camisani, 2018; Winengan, 2019) to Latin America (Loperena, 2017), from Northern (Oklevik et al., 2019; Stanley, 2020) to Central (Smith et al., 2019) and Southern Europe (Schiermeier, 2004; Carballo et al., 2019; García-Hernández et al., 2017; Ioannides et al., 2016; Navarro-Jurado et al., 2019). More detailed insights might come from the real-time observation of oppositional movements ${ }^{1}$. Beyond the mainstream narrative of the creation of jobs-advocated by both governments and unions, often in spite of the actual working conditions datathe professed benefits to the local economy often conflict with the well-being of local dwellers, the built environment, and the surrounding natural environment ${ }^{2}$. According to Calzada (2020), touristification often causes "gentrification, privatisation of public space, inherent conflicts between visitors/tourists and residents/ locals, environmental damage, and precarious working conditions". Moreover, it is often blamed for threatening the very survival of the social fabric, as well as of the urban texture and functions as we know them. While addressing the most common phenomena related to urban tourism, Postma et al. (2017) review the concepts of "touristification", "disneysation", "gentrification", "lowering housing supply by increasing rents and real estate prices", and "lowering quality of life for local residents". When the side effects of overtourism become mainstream, it is often too late to intervene, and emergency policies are therefore implemented, for example through special laws or urgency bills, which are scarcely democratic by definition (see Agamben, 2003). In this field, we can mention the setting of caps on arrivals, or timid attempts of management through taxation and ticketing (Nepal and Nepal, 2019; Salerno, 2018b; Dal Bianco, 2019), as recently proposed also for Venice, but indiscriminately affecting tourists and friends or relatives hosted by residents (Comune di Venezia, 2019).

Sometimes, economically tempting responses to emergency actions are proposed to local administrations, such as "compromises" aimed at "maximising the monetary gain" from tourism while trying to satisfy local populations' "desire to control the undesirable effects that tourism exerts" (Bertocchi et al., 2020). Anyway, both in propaganda acts and in scientifically valid scenarios, a systemic perspective is still lacking, and so is a vision aimed at solving the problem on the long or medium run. A satisfactory solution sometimes is not even pursued, either for the difficulty of a belated action or for the absence of any real will to structurally intervene toward a lasting but not immediately "profitable" resolution, able to gain the placet of the dominant "stakeholders". If "normality" is already an issue in many tourist destinations, exceptional events can only worsen the situation. In ecological or agricultural systems (Lin, 2011), resilience is usually defined as directly proportional to diversity. Paraphrasing Scott (1998), far too seldom is it noted how an extreme oversimplification of a social system (let us say, a city) implies the same failure risks as an oversimplified natural system (e.g., the artificial monoculture of a given vegetable). As an economic monoculture, a touristified destination is very vulnerable to external events, including the aforementioned exceptional situations. Be them a pandemic, an extreme weather event, a war, a famine, a resulting or simply re-emerging economic crisis, if the tourist inflow slows down or even stops, the already jeopardised life and economy in a tourist destination are further affected, and might ultimately collapse. Therefore, even the narrative of job creation, already biased per se, is extremely precarious, as is the touristic destination itself.

Time has come to systemically and lucidly question the actual effectiveness and desirability of tourism as a local economic engine. As a deceptive "magic recipe" to attract foreign money, tourism introduces controversial aspects that are often patched up just by coupling the word "tourism" with the empty adjectives "green" or "sustainable". In particular, we here focus on the fact that tourism would be expected to match the notion of sustainability, at least in its definition of "ability to maintain something in existence without interruption or diminution" (Engelmann, 2013). At the same time, in the aftermath of a global crisis, the social and economic effects of tourist monocultures ought to be also addressed, and we might match this aspect with the notion of resilience (Holling, 1973; for urban resilience, see for instance Sanchez et al., 2018). Concerning the first aspect, a recent research stream can be identified, assessing the global ecological impacts of tourism (for example, Lenzen et al., 2018) or calling for a reduction of tourist flows as a response to both ecological and social concerns (Andriotis, 2018; Fletcher et al., 2019; Higgins-Desbiolles et al., 2019; Valdivielso and Moranta, 2019). As to the second aspect, much less literature is available. Nevertheless, the present global pandemic emergency has been proposed as a turning point to rethink societies and economies. The comprehension of the dynamics of a crisis suggests new, transdisciplinary thinking on the design of social systems and of their connected economies. As expressed recently for example by Haldane, we might expect "periodic, self-generated tipping points, in which they shift quickly into a new state from which they cannot return" (Haldane, 2020), due to their "classic robust-yetfragile properties" (Haldane and May, 2011). Among these economies and societies are of course tourism and tourist destinations ${ }^{3}$. Even business voices now bow to the facts, admitting that-in the aftermath of the Covid-19 emergency-travel-asusual will no longer be sustainable, with impacts on both the environment and local communities, and sometimes even without significant economic benefits (Tembo, 2020). HigginsDesbiolles (2020) maintains that a critical analysis of the shutting down of travels, tourism, and hospitality can now uncover "the ways in which tourism has supported neoliberal injustices and exploitation". However, she warns that "responsible" approaches will not be enough, and a community-centred framework is needed to meet "the rights and interests of local communities" within the "social and ecological limits of the planet". For a general city to be resilient, to resist and to adapt to external disruptions, one basic condition is that it cannot depend solely on imported inputs and capitals (Cristiano et al., 2020). The question posed by Norman (2018) on how to imagine future 
sustainable and resilient cities remains open, while we propose different possible replies to her statement that "[a]s cities grow they will become stronger and more independent and autonomous economically as a result of their wealth" (ibid.).

If a significant increase in academic publications on tourism dynamics has been recorded in recent years, a theoretical framework is still lacking for this phenomenon (Cassinger and Månsson, 2019). The "tourist city" has been defined as "an original novelty of our modernity" (d'Eramo, 2019), a ubiquitous, familiar, yet not elaborated phenomenon, eluding questions and neutralising thinking (ibid.). Even in the presence of a wide literature, its conceptual elaboration is still poor and fragmented (ibid.). This reminds us of the "pulsing paradigm" by which systems thinkers and ecologists Odum and Odum (2008) acknowledge that the culmination of our civilisation has passed, and that all circumstances are inviting or forcing us "to adapt to the future". A novel conceptual elaboration of post-pandemic prospects is therefore necessary for tourist cities.

In this paper, we suggest some paths for such cities to come through the Covid-19 crisis and other possible global emergencies. The current pandemic can represent a turning point to highlight already present structural issues and try to face them by a collectively rethinking of cities, starting from their dwellers. Epistemological tools rooted in systems thinking (see section "An epistemological tool rooted in Systems Thinking") are applied to the study of a general tourist city. An Italy-based focus is also dedicated to the iconic tourist destination of Venice. For European cities, the link between urban planning and tourism has been rarely addressed so far (e.g., Shoval, 2018). Even without any focus on tourism, a systems thinking approach to the sustainability and resilience of societies and urban systems is offered in Cristiano (2018), Cristiano et al. (2020), and Gonella (2019). Here, a conceptualisation is now proposed to envision a future beyond the unbearability and fragility of tourist cities, and thus to support their dwellers in imagining and planning such a future, free from barriers but according to their needs and priorities. Among the guiding questions are:

(i) to what extent a tourist city is or can ever be "sustainable", affected by a minimal impact while preserving long-term sustainability and authenticity;

(ii) what the real goals of touristic transformation are, i.e., for what and for whom cities and other destinations are touristified;

(iii) whether or not pursuing local well-being is actually part of such goals, as often professed, and to what extent alternative strategies can compete with it.

By responding to these questions, the compatibility between mass tourism on the one side and lasting urban life, economy, and well-being on the other can be explored, considering that to the best knowledge of the authors no study has been addressed so far through this approach. Moreover, the outbreak of the Covid19 pandemic might represent an unprecedented opportunity for meditation and transformation. By means of systems diagramming, the resource inflows and outflows of a tourist city are described, together with its metabolic structure. Some novel insights are provided about the sustainability and resilience of tourist cities, together with some prospects for desirable, ecologically sustainable, and socially just recoveries, compatible with well-being and local priorities.

\section{Methods}

An epistemological tool rooted in Systems Thinking. A tourist city is here studied both in normal conditions and during the global Covid-19 pandemic. This is done by using a Systems
Thinking (ST) epistemological approach. A descriptive framework of a tourist city is developed by the energy systems language (Odum, 1983), using stock-and-flow symbols (see also Sterman, 2012). The development and formalisation of ST derived from the pioneering works by von Bertalanffy (1968) and Forrester (1973), then further refined and developed by several scholars, with different approaches to meet different scopes. In particular, we refer here to the work by ecologist and systems scientist Howard T. Odum $(1994,2007)$, who developed a sophisticated methodology based on energy symbolism, able to describe and-when needed - quantify the dynamic operation of complex systems, including both natural and human-made structures. This can be made by a single research tool, derived from a comprehensive stock-flow diagram encompassing all the resources that participate in the systemic dynamics, including matter, energy, infomation, labour, and economic flows. Systems Thinking has been used in several fields, ranging from social sciences or management to environmental and ecological studies (see Checkland, 1981; Ballé, 1994; Haines, 2016; Capra, 1985; Maani and Cavana, 2007; Boardman and Saucer, 2008). From an epistemological perspective, it shifts the attention from the linear description of factual features of a system, in terms of chains of local cause-effect processes, to the study of the structure of pattern configurations, resulting from the self-organised network of feedbacks that ultimately define the system stability, resilience, and adaptation capacity (Sterman, 1994; Meadows, 2008). The understanding of the pattern configuration of a system does not necessarily require quantitative analyses. As detailed later, the adopted method should not be confused with self-standing approaches such as System Network Analysis or Stock-and-Flow Analysis.

First and foremost, a study based on systems thinking entails the definition of a systemic diagram, including stocks, flows, and processes that are relevant to define how a given system operates at a given level of detail (Luna-Reyes and Andersen, 2003; Bellinger, 2004). The boundary of a system has not (only) a physical meaning, but rather separates what is considered as the external drivers and what happens inside the system itself, defining the inflows and the outflows of resources that participate in the processes within the system, a choice that is ultimately related to the very object of the study. Stocks might be ultimately expressed-when required-by extensive, countable variables whose values describe at any time the state of the system at the desired level of the study, providing a description of the main elements and the main resources participating in the urban metabolism, including the network of feedbacks that constitute the dynamic features of the city. Processes are whatever able to change a flow, and represent the intersection points of different kinds of flows that produce a certain outflow from the process, including the controls exerted by other stocks in the system. This is the core of systemic diagramming: the network of resource flows and controls creates a network of feedbacks, arranged in a hierarchical structure (Bossel, 2007) operated at different complexity levels and with different time delays. Flows and stocks can be either material or immaterial. The systemic components can be then grouped to highlight their main mutual influences (Gonella et al., 2020). By a proper definition of the analytical expression of the flows, one can eventually set up a computational simulator of the system dynamics, which represents a potentially powerful tool in any decision-making procedure. This task is well beyond the scope of this paper, but the idea to start facing the problem of the sustainability of tourist cities by this kind of quantitative analysis certainly deserves all the attention. In fact, in addition to an overall understanding of the operation of a given system, one of the main goals of a systemsbased analysis is to find the material or immaterial systemic local sub-structures upon which the system depends, where an even 
very small change can affect the whole system. They represent the systemic places where to intervene, namely, the leverage points (Meadows, 1999).

It is important to clarify that the words "system" and "systemic" as used in the ST framewok at hand have not the same meaning than in a System Network Analysis context, and in general within the related computational approaches. While both Network Analysis and Systems Thinking aim at describing a system as a whole, the former still retains the scale of the microlevel, considering a system as the collection of a large number of elements, whose dynamics are investigated thanks to the availability of big data and specific mathematical and statistical tools. On the contrary, ST starts from the identification of a limited number of state variables, those necessary to model the resource flows and the feedback networks that describe the configuration patterns of the system dynamics. Our systemic framework is intrinsically flexible, and can be applied to different tourist destinations, even though the urban level is here prioritised. In the construction of the diagram, the pivotal role played by the tourism sector will be, therefore, specifically highlighted.

Different versions of systemic approaches, with different and often diverging theoretical bases, have been applied sectorially to tourism planning, yet without a comprehensive territorial view, and with no focus on urban European contexts. This is for instance the case of some seaside destinations in Oceania and South-Eastern Asia (Walker et al., 1998; Schianetz and Kavanagh, 2008; Van Mai, 2010; Nguyen and Bosch, 2013; Mai and Smith, 2015) or urban tourism sustainability assessment in China (Lebe et al., 2014). Nevertheless, most of the literature tends to focus on local sustainability indicators, sometimes through quantitative simulation (Lazanski and Kljajic, 2006) or simple causal loops (Roxas et al., 2020). These approaches actually use some kind of systemic perspective, but present two main drawbacks: first, the use of static indicators does not capture the dynamics of a system's operation, being unable to describe the action of the most relevant feedbacks in determining the evolution of a problem; second, a systemic description based only on causal relationships, without a common quantitative ground for their description, cannot be converted into an analytical tool able to address suitable leverage points for intervention. Jakulin (2017) ventures in the definition of a complex tourist system but offers no prospects and does not encompass the urban level. Conversely, Pollock (2016) addresses urban dynamics through looped thinking, however, not considering the tourism sector. Although still different, a methodological example closer to our work is offered by Farrell and Twining-Ward (2005), who describe complex system dynamics (SD), suggest a paradigm shift, but start from different research questions .

This work is placed, therefore, in a new thread, where a first conceptual step is moved toward an evaluation of the sustainability and resilience of urban systems (Cristiano et al., 2020) by exploring possible structural scenarios, and pointing out systemic flaws, potentially studied in terms of resources flows dynamics. The manifold aspects of sustainability and the various levels of interconnection and dependency are then addressed, as part of the general prerequisites for resilience in a tourist city. Alternative scenarios are presented as a basis for possible future quantitative and qualitative analyses, as well as for groundbreaking proposals aimed at satisfying local priorities. As concerns the Covid-19 pandemic, the same approach used for the present study has been also applied in a systems thinking-based description of the epidemiological communication and management (Gonella et al., 2020).

It is worth stressing that this systemic representation can have a two-fold epistemological valence. On the one hand, it allows to understand how the configuration of the resource flow network adapts to the socio-economic choices of a tourist city. On the other hand, it lays the basis for the creation of an analytical representation of the metabolism of a given city (see Xue et al., 2018), able to describe quantitatively its dynamics in response to external changes in socio-economic or environmental driving forces. Needless to say, this is going to become of vital importance in the definition of adaptation policies able to build up some degree of resilience upon the effects of climate change and of other uncertain external drivers.

Venice, Italy: an extreme yet not isolated case. Several Southern European cities face a delicate situation, due to financial crises and/or debts, where the attraction of foreign money is seen as a major opportunity for economic recovery. Still, urban changes aimed at tourist trasformations do not follow any comprehensive urban planning, and lack an integrated perspective able to consider the three traditional dimension of sustainability-social, environmental, and economic-altogether. The real goals of touristic transformations are never explicitly addressed, in spite of their relevance in the systemic configuration and operation of a tourist city. In this work, we address Venice, Italy as an emblematic example, while some minor comments are dedicated also to Rome and Naples, the latter undergoing-at a smaller scale-a different stage of a similar tourist transformation. Venice is a globally recognised example of a dying city. In addition to the global human-induced threats to its delicate environment (Reimann et al., 2018), its current inclusion in the World Heritage Site list is being questioned due to its poor management (UNESCO, 2015, 2019). The often non-reversible consequences of the transformations of Venice and its Lagoon are most of the times linked to direct and short-term profit, with tourism as the main trigger of such mechanism. Controversial measures have been discussed and undertaken at both the city and the national government levels, supposedly aimed at limiting and selecting the inflow of tourists, e.g., access taxation and number limitation policies.

Based on official records only (Città di Venezia, 2018), registered tourists in the regular accommodation facilities of the City of Venice increased from 4.2 in 2013 to 5.0 million in 2017, and overnight stays from 9.8 to 11.7 millions. No real off-season can be defined for Venice, and $86 \%$ of visitors usually come from abroad, mostly by airplane. Both hotel beds and complimentary accommodation facilities increased significantly in the same period: the former from 29 to almost 31 thousands $(+7 \%)$, the latter from 2.8 to 6.0 thousands $(+114 \%)$, with available beds going from 18.7 to 32.5 thousand units (+74\%). In 2017, 274 hotels were present, in the sole insular Old Town (or Historic City), plus 4,808 registered tourist apartments, 377 room rentals, and 291 bed-and-breakfast structures. Altogether, they were offering over 43,000 beds at the end of 2017 , increased to 49,260 in 2019 , i.e., $+500 \%$ compared to 2008 (Bertocchi and Visentin, 2019). On the other hand, the most recent statistic figures report 52,143 inhabitants at the end of 2019 (Città di Venezia, 2020): $-21.5 \%$ in 20 years.

This means that, in a progressive diversion of housing assets, nearly half of the beds in the city are currently dedicated to tourists. More hotels and other accommodations are being built, refurnished, or converted while this manuscript is being written. As frequently happening in touristified cities, this process of expulsion of the local population has been encouraged by changing the urban functions of buildings, apartments, and businesses, often made by dispensation from the original urban plans, and sometimes through the selling off of public buildings offering public services to private enterprises seeking profit in the 
tourist sector (see for instance Salerno, 2018a; Borrelli, 2018; Cristiano, 2019). For instance, restaurants had a $+160 \%$ growth between 2008 and 2019 (Bertocchi and Visentin, 2019), usually replacing regular shops and workshops. We will not further focus on the connected decline of urban services for residents, nor on the rise of prices for housing rents, housing purchases, and overall living, directly or indirectly connected to the above and anyway pushing residents out of the city. We just provide some evocative images: cultural palaces such as Teatro Italia $^{5}$ and Cinema Rossini $^{6}$ are now hosting grocery stores; and the former headquarters of the postal services at the thirteenth-century palace Fontego dei Tedeschi alongside the Grand Canal has been transformed into a luxury mall ${ }^{7}$.

Moreover, further assets that switched from local life and economies to tourist hospitality can be found in the choice of land consumption for new hotels, both in the mainland and in the Old Town (Hotel Domani, 2018; Il Gazzettino, 2019, 2020; La Nuova di Venezia, 2020a), and for the enlargement of the city's airport. Since 2002 (Architonic, 2019) and up to 2019, the main Marco Polo air station has undergone frequent major expansion in both the terminal and the trail areas. After that, the capacity of the air terminal has grown by $+170 \%$ in the period 2000-2018 (after Venezia Airport, 2019).

These data indicate, directly or indirectly, an increasing trend in arrivals, at least until the recent abrupt slowing down. Moreover, an increasing number of daily cruise passengers has been also approaching the city in the past decade. Annual cruise passengers in Venice reached 1.6 millions in 2018 (Porto di Venezia, 2019), mostly concentrated in weekends, thus averagely pouring more than 30,000 additional visitors ${ }^{8}$ all of a sudden into the city-and even much more in peak season. Rough calculations only based on the reported official data suggest registered tourists are at least twice the resident population throughout many months in the year. Such ratio is further increased if we also include non-registered tourists, tourists sleeping in cheaper accommodations out of the city, and daily travellers. Cruise tourists do not directly affect housing but rather other urban functions, not to mention residents' discomfort and possible expulsion for the noise and the poisonous gases released from the constantly running ship engines (the harbour is adjacent to residential areas).

With such numbers in an economic monoculture, significant portions of the salaries come from (and are therefore closely dependent upon) the tourist sector. Workers and businesses depending on tourism are not limited to hospitality, but also include, among others: public and private transportation; guided tours; souvenir and other regular shops; bar, restaurants, other catering services, and their suppliers; cultural exhibitions and events. After an exceptional high tide in November 2019 and the worldwide iconic appearance of the flooded city in the mass media, Venice underwent tourist cancellations in the following months (RAI, 2019; La Repubblica, 2019), presumably due to the fear of a spoilt "experience". At the outbreak of the Covid-19 pandemic ${ }^{9}$, international flights almost immediately started to decrease globally (Iacus et al., 2020) until full bans in many countries, together with travel, tourism, retail, and transportation in general (Duan et al., 2020; Moslem et al., 2020). Of course, the related lockdown brought heavy consequences on several economic sectors, including tourism (Fernandes, 2020). With decreasing and later ceasing travels due to fear, precautions, and even lockdown constraints, Venice as a mass tourist destination has almost immediately ended up "on its knees" (Casert, 2020): an emptied city with many unemployed or underemployed people, and the beginning of an economic depression not limited to the sole hospitality industry ${ }^{10}$. Some scanty voices in the city and beyond were already denouncing the unsustainability and fragility of such a monocultural socio-economic system. Likely, no one was expecting that similar predictions were going to become tangible so soon. While the present manuscript is being written, the city is undergoing severe conditions, and more and more people are becoming familiar with such warnings as well as with the need for a change ${ }^{11}$.

In this contribution, we propose a conceptual integrated description of a tourist urban system, aimed at describing its criticality and supporting a just, desirable, sustainable, and resilient shift. Knowledge production follows a 5-year weekly monitoring of news, the participation in public debates and meetings in Venice, Rome, Naples, and Barcelona, direct exchange with tourist practitioners and workers and with active citizens and groups (including scholars and activists from the above cited SET network), and several contributions to academic and non-academic conferences and meetings, in order to receive feedback and refine our results. Our study shows that Venice is not a unique example, thus the systems diagram for a general tourist city presented in the next section may hopefully provide further support to other tourist destinations.

\section{A tourist destination through an original systems diagram: results and discussion}

A look at the diagram: goals, assets, and metabolic flows of an urban system. The qualitative results of the systems thinking approach-in particular, the systemic diagram reported in Fig. 1 - are here discussed. They represent a comprehensive description of the dynamics and threats of a tourist city by means of a conceptual elaboration of the related system, encompassing urban (local) life, economy, and resilience in the presence of uncertainties and hazards, such as for example the recent Covid-19 pandemic. The possible functioning and leverage points of the system at issue are illustrated, thus assigning an expected impact to the existing and prospective measures to face its problems. As a general human system, a city may require local renewable and nonrenewable sources to be created and maintained. In its gradual transformation from a "traditional" society into a contemporary Global Northern one (see Cristiano, 2018), a city also requires imported materials, fuels, electricity, food, water, and other goods and machinery to keep its pace. Also, it often needs imported labour in addition to the services (indirect labour) required to import the aforementioned items. Usually, urban processes produce extra products and services to be exchanged for money, through which the imported products and services cited above can be purchased from the outside. Theoretically, the goal of an urban system should be the safety and well-being of its dwellers.

A city is here represented as a system directly relying on a "local environment" (on the left), where natural assets and resources provide the minimum preconditions for the urban metabolism (air, solar radiation, land, etc.). Within the urban system, all the typical stocks of a city are grouped in the "Urban assets" stock. This is mostly composed of the built environment and of the urban ecosystems, among which: infrastructures (transport systems, power, internet, and other utility networks, etc.); houses, offices, markets, hospitals, and other buildings; rivers, channels, parks, and other public spaces. Fuelled by local and imported resources, including labour, such urban assets allow for the "Urban life and general economy" processes to happen. These are mainly related to human and other animal living (eating, dwelling, socialising, studying, recreating, etc.), urban services (education, transportation, health services, welfare, beaurocracy, etc.), logistics and transport, ecoservices (biota conservation, pollution control, etc.), and to the general urban economy (industry, commerce, and tertiary-usually the primary 

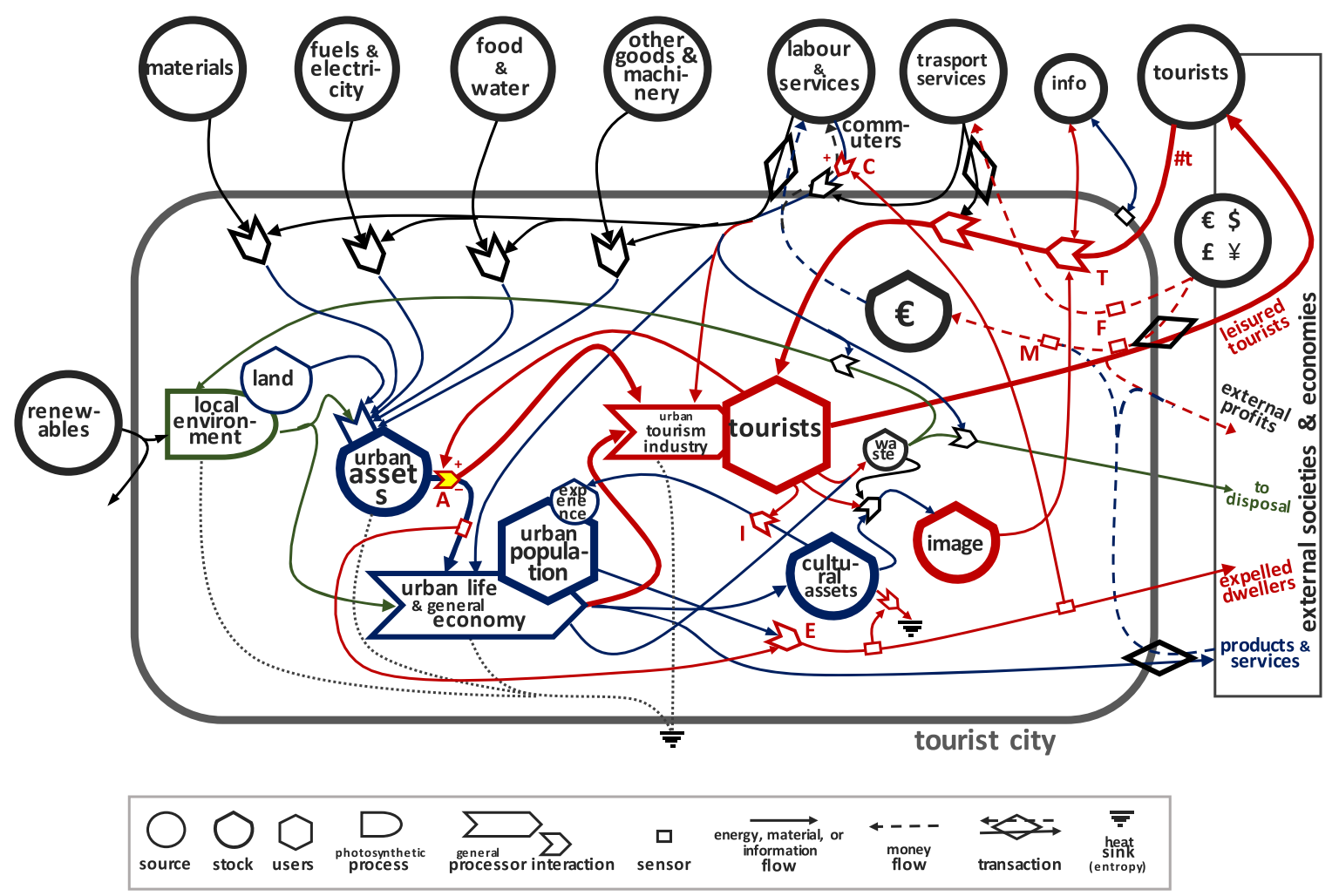

$A=$ asset allocation; $E$ = population expulsion; $C=$ daily labour import; $I$ = influence on habits; $T$ = tourist attraction;

$\mathrm{M}=$ economic monoculture sensor; $\mathrm{F}=$ fleeing money sensor; $\# \mathrm{t}=$ number of attracted tourists

Fig. 1 Systemic diagram of a tourist city. Blue stocks and arrows represent the main sectors and flows of any city, while red colour highlights the elements connected to tourism activities. Process $A$ is highlighted since it represents a crucial leverage point where both urban planning and policies or other actions toward social equity can intervene.

sector is dwarfed by the rest). In a steady-state or regularly oscillating economy, these address and maintain the socioeconomic life of any city, and are represented by the blue stocks and flows in the figure. Blue-marked urban stocks and flows are generally present before and irrespective of any tourist "vocation". Usually, the economy of a general city produces surplus products and services, to be sold for making the money needed to pay for the first imported inputs into the city. So far, so good. Throughout the years, a city also produces culture and wellbeing (see also Cristiano, 2018). This is of course something everchanging, continuously depending on the processes through which they are produced. Anyhow, such an immaterial stock shapes the experiences of a given urban population, including its priorities, its features, and its desires: i.e., through recursive processes and feedbacks, culture, well-being, and related experiences can all represent a leverage point able to change the configuration of the entire system. Let us keep this in mind for a short while.

In parallel, the culture and the well-being of a tourist city help the city itself to build a plausible or artificial image. Some economists, managers and alike would maybe call it a "city brand", but the image better reflects something that can emerge without a deliberate plan, and is not necessarily profit-seeking. This image can be either material or immaterial. The former can refer to art and architectural masterpieces, while the latter is made of intangible fascinating aspects, like for example the legendary Italian "dolce vita". This image represents a proper stock, and is made of all the information that can make a city attractive for tourists. The action of the image stock is that of increasing the tourist flow (\#t in the figure) by the control exerted over the process $T$ (tourist attraction) in the figure. It is worth noting that, in particular situations, a "negative" image may also take place, since part of the image is due to environmental, social, and economic conditions that might be not under control. This is the case for example of the high water phenomenon in Venice, which above a certain threshold of frequency and intensity discourages the coming of further tourists. When such an image is known outside of its original location, it is combined with other information coming from either inside or outside our system at issue, and might cause someone to be attracted by that location. This may be seen as the beginning of the tourist phenomenon. Visiting a city did not use to seriously affect the urban configuration for centuries or even millennia, so tourism can be regarded as quite a novel phenomenon ${ }^{12}$.

The peculiarities of a tourist city. We are here interested in what makes a city a tourist city. We can say that this distinction originates from a competition in the function-and, thus, in the allocation-of the urban assets. The presence of an important tourist phenomenon within the city is represented in Fig. 1 by the red stocks and arrows, whose main effect is that of splitting the outflows from the urban assets to power the tourism industry, i.e., those urban functions specifically dedicated to accommodate, feed, and entertain the city's visitors. Such splitting represents a divertion of physical resources from citizenry to tourists. From a systemic point of view, the main effects of the urban tourism industry is the activation of some peculiar reinforcing feedback. First of all, a direct one is represented by the process $A$ (assets allocation), which indicates how an increase of the stock of tourists determines an increase of the flow of dedicated resources to the tourism industry, which in turn makes the tourists stock further increase, in a reinforcing loop. Through this, the tourism 
industry diverts to itself the resources originally dedicated to the citizenry (i.e., decreases the flow from the urban assets to the urban life and economy).

So tourists are attracted, and tourists arrive, temporarily brought into the systems diagram by means of transport services. The split of the outflows coming out of the stock (containing the mentioned urban assets) diverts heritage, spaces, and material or immaterial resources from the urban life and general economy to the urban tourism industry. The process requires to accommodate tourists after they are attracted to the destination.

To be fuelled, the tourism industry process usually requires further labour and services-even simply remote labour to help with promotion, translation, booking, etc.-and, above all, parts of the urban life and general economy. Local workers are involved, but also tourists might partially share portions of the urban life and general economy (e.g., by visiting museums, shopping and eating in places for locals and/or for both, using/ purchasing otherwise exported general products and services, etc.). Such coexistence implies the rearrangement of urban life, general economy, and tourist-resident interactions, and interferes with the evolution of the culture, well-being, and overall experiences of the urban population. Interestingly, while most agree that a local community influences tourists with its arts, architecture, etc., the opposite is rather unperceived. When a tourist transformation starts, by changing and diverting urban assets to ease and please the tourist presence, consequences soon become tangible. A frequent one is represented by the gradual replacement of housing ${ }^{13}$ and local urban functions with hospitality facilities and tourist businesses and shops, mostly driven by increasing prices, thus representing a substitution by census, and by class. This is the first and most frequent aspect of what is often defined as touristification, usually happening together with a similar phenomenon called gentrification (Jover and Díaz-Parra, 2019). The interconnectedness of touristification and gentrification can lead us to coin here the word gentritouristification.

Leverage points: image and tourist-resident competition for the allocation of resources. Gentri-touristification can imply the relocation of residents towards less central areas within the same city-as illustrated in the systems diagram of Fig. 1-and this can ultimately result in the expulsion of resident population out of the city. Such drainage of the urban population recipient stock is directly linked to, and activated by, the split in the urban assets. From a systemic point of view, the urban dwellers of Venice are pushed out of the system by the action of the tourist stock, and are represented in the figure by process $E$ (expulsion). This indirectly participates in a reinforcing feedback, decreasing the users stock of urban population and thus potentially accelerating the diversion of urban assets from the urban life to the tourism industry. The expulsion of city dwellers also implies an increased need for workers from outside the urban system at issue, hence for commuters attracted and transported into the city. At the same time, the levels of local culture, well-being, and other immaterial assets are depleted, also affecting the very image originally attracting tourists. In principle, such depletion should negatively affect the image of the city, ultimately providing a balancing feedback with a decreased attractivity for visitors. This is an intrinsically self-destroying aspect of touristification: the image and "authenticity" of a given destination attracts tourists, and the local transformations to host them cause a depletion of the image itself, thus potentially discouraging tourism for the original attractors change. The city and its population are transformed and weakened, now depending upon visits and barely able to pursue their well-being, or even survive, with an uncertain tourist industry. This can be well defined as a balancing feedback, preventing a phenomenon to grow endlessly. Nevertheless, successfully reaching such a balance is not at all granted. On the one hand, it competes with the reinforcing feedback that tends to maximise the resource use by tourism, significantly depleting the urban life and economy. On the other hand, despite the decrease in the city's image, the city might still be attractive for other kinds of visitors, not necessarily interested in something "authentic". In both cases, this clearly highlights the duality of the "authenticity" of a place and, elaborating Debord (1967), its banalisation, of which touristification can be identified as a prodrome. From a similar perspective, the issues of the positive and the negative effects of touristification, as well as of the optimal amounts of tourists simply lose their reasons to exist. The competition for the use and allocation of the urban assets in a tourist city represents, therefore, a major leverage point. A small change produces much larger effects onto the whole system: both its configuration and its priorities can change. If matched with the widely unquestioned profit-maximising goal of the city, opening a diversion channel from urban life and general economy to the tourist industry would therefore doom the city to exhaust the former to the advantage of the latter. This is after all compatible with the "vicious circle" of tourism development in heritage cities, as addressed by Russo (2002).

Systemically poor sustainability and resilience. The boundary between regular tourism and overtourism is hard to be set. From a systemic perspective, "regular", "sustainable", or even "green" forms of tourism may just correspond to different equilibrium regimes for the same systemic configuration. This configuration is self-organised such to guarantee a certain resilience that is lost as the system shifts to an overtouristic one. The reinforcing feedback $A$ can be seen as a trigger for touristification. It might even happen that-due to the well-known Jevons' paradox (1865, see Alcott et al., 2012)-an increase in the efficiency of the tourism industry accelerates the draining of urban assets from urban life and general economy, while depleting the urban system andultimately - the tourism sector as well. Systemically speaking, this is also perpetuated by market attempts to "democratise" tourism, for example by redistributing some dividend shares from tourist apartment rentals to urban projects. This is what the Fairbnb platform proposes (Foramitti et al., 2020), thus making critiques harder while still diverting the urban assets and therefore contributing to the aforementioned "vicious circle". As concerns the flows of money, they are represented by dashed lines in the diagram. In fact, they are virtual, geobiophysically non-existing flows, only representing information that is exchanged for other resource flows (monetary transactions are expressed in the figure by the diamond symbol). The exchange occurring for regular products and services is common to any non-isolated city. A transaction typical of a tourist city is separately drawn, consisting of the exchange of money for leisure, i.e., what is monetarily paid by visitors to stay, eat, etc.-in few words, as expressed in the figure, for their leaving the city system as "leisured tourists". The monetary flows in the figure can reveal that only a portion of them enters and/or stays in the urban system, as most of the money builds up external profits. Such information is collected by a couple of sensors ( $F$, fleeing money), detecting monetary flows related to tourism but not increasing local monetary wealth. This is an often neglected aspect of tourist issues, but who advocates economic benefits for a tourist destination tends to forget or opportunely disregard that hospitality facilities, food and beverage catering services, shops, etc. are frequently owned by foreign or at least external capitals, and that profits and dividends from shares are usually directed elsewhere, or anyway 
concentrated in few pockets. This is even more evident if we focus on the transport services required to bring tourists in: be it a bus, train, or boat trip, or rather a flight, a transport service is usually provided by external companies. On the one hand, this means that some money simply does not reach the final destination; on the other hand, that tourist arrivals, and so the regular functioning of a tourist city, are bound to something upon which the city has no control. From a systemic point of view, the possibilities to at least partially alter the urban economy in terms of money distribution are linked to the overall change in the operation of the urban assets. This is in turn related to the configuration of the system, which can be changed by the urban population.

The increasing expulsion of residents and the corresponding increase in commuters both sharpen the dependence upon something or someone coming from outside the system. This is added to the abdication of primary or secondary production, replaced by the import of all what is needed. The resilience decreases and the uncertainties and risks of a tourist monoculture become higher and higher. In order to keep its pace, a tourist city requires at least a steady rate of arrivals from the outside, in order to attract capitals and provide the importation of livelihoods. This process progressively weakens the urban system. At the same time, the control over the whole process progressively diminishes, proportionally to touristification. Altogether with the urban system, also its environmental components are depleted by a cumulatively increasing tourist presence (in the figure, this is expressed as a waste increase). It is worth stressing that, in Venice, the lagoon environment is as fragile as the city itself, and this condition makes the interconnection between the city and its support area even more critical. From a systemic point of view, the lagoon provides essential ecosystemic services in terms of pollutant dilution (even though Venice remains one of the most polluted areas in Europe), support to local fishery and aquaculture, and-of course-support to cultural activities.

The import of livelihoods depends on the import of capitals, and the import of capitals on the attraction of workers and tourists. However, two issues can be observed. First, in an overtourist city the monetary inflows depend on tourist arrivals. A lack of arrivals might ultimately result in a lack of money to purchase even basic livelihoods. The rate of overall dependence upon foreign capitals is detected in the diagram by the sensor $M$ (economic monoculture sensor). Second, such attraction is in turn depending on the image of the system, progressively depleting, and on a wide range of internal and external information and socio-economic conditions. Among the types of internal information, we can recognise a diminished appeal of a general tourist destination due to the loss of "authenticity", or rather to possible increasing crime rate, spoilt landscape ${ }^{14}$, health and sanitary emergencies, hygiene scandals, extreme weather conditions ${ }^{15}$ or so-called natural hazards ${ }^{16}$, famine, strikes and riots, price increases, new bills and laws ${ }^{17}$, austerity measures, and so on. At the outbreak of the global Covid-19 pandemic, all of this started to become less and less hypothetical and blur.

Referring to the systems boundary provided in Fig. 1, the more the dependence upon external inputs and information, the less the resilience of the system. In addition to the impacts of its "proper" operation, a tourist system also exhibits risks and uncertainties to survive even before its self-destruction. Unlike profits and dividends, risks and impacts onto the city are well distributed. Even profit-seekers are affected, starting from small and medium enterprises. If the social fabric is compromised, the ecological conditions degraded, and also the economic sphere endangered, then the three dimensions of sustainability depict a failing scenario.
Venice, Rome, and Naples. In Venice, all of what is illustrated in this section is present, and possibly amplified. Its local dwellers tend to be directly expelled even before relocation to more peripheral neighbourhoods, since its surrounding lagoon represents a physical limit for which touristification corresponds to expulsion to another city, town, or directly to the wide anonymous urban sprawl of region Veneto (thus abruptly losing crucial information packages represented by hundred-year experiences of living and interacting in a unique urban context). The numbers of tourist presences and permanent population, described above, provide a clear picture of such a phenomenon. With some exceptions, Venetian urban life and general economy have been mostly converted to-not just diverted resources from-the tourism industry. As a consequence, urban life and general economy, urban population and its experiences, and Venetian culture and well-being are all jeopardised: this is marked by the progressive emptying of the "Cultural assets" stock in the diagram.

Conversely, the first Italian tourist destination, Rome, mitigates touristification by expanding its assets into its surrounding countryside, which from a systemic perspective constitutes the socalled support system. The city centre is touristified or at least gentrified, and residents are pushed out towards the outskirts. This happens while fertile soil is lost, road traffic and air pollution are increased, and the available free time decreases together with the overall life quality for its dwellers: "la dolce vita" is now less than a temporary experience for tourists, significantly detached from local reality. Naples, an emerging tourist city in Southern Italy, is also being progressively touristified its historic centre. The main attractor there is widely associated with its "authenticity", its less explored daily urban life in the narrow streets of the city centre, together with cheap, tasty food. Unfortunately, there is no much to add to what stated above: even without reaching dramatic limits, the attractivity of Naples is determining-and being affected by-the loss of its characteristic life, the increase of prices, and the decrease in overall quality, starting from food.

Back to Venice, on the one hand the jeopardisation of the city's social fabric and economy have already caused a significant worsening of the city's image, so that even the inclusion of Venice and its Lagoon in the UNESCO World Heritage List is currently put into question. On the other hand, the "conversion" of the city into a tourist destination causes a decreased resilience and a matching uncertainty, where the dependence upon external drivers has gone more and more out of control. If the Covid-19 pandemic is influencing most of tourist monocultures throughout the world, the crisis of Venice had started months before, with the spectacularisation of its flooding: following its highest and most abrupt and violent tide ever ${ }^{18}$, visitors were scared to the point of cancelling reservations for the following semester. The interruption of tourist flows to Venice between late 2019 and 2020initially voluntary, then forced-has caused the many precarious workers to lose their job, and many small and medium entrepreneurs and artisans to get into debt when not directly to default. A tertiary, consumer city producing almost none of its livelihood has then started to rely on poor governmental subsidies $^{19}$ and on mutual solidarity ${ }^{20}$. If local associations, movements, and representatives were recently debating on "alternative solutions" to tackle overtourism, what is needed now are much more important considerations and decisions. This is what this contribution is aimed at supporting.

Profit, well-being, and the real goals of a tourist destination. Tourism would bring money to any given destination, yet tourist transformations imply clear impacts, as outlined in our Introduction. Zanardi (2020) proposes that "tourism relies on a 
mainstream narrative according to which-even through special regulations-tourist development would be the only possible form of economic growth in some geographical contexts", supposedly able to yield large and prompt profits, boost employment, and help endangered economies ${ }^{21}$. However, she maintains this narrative prevails when all other options are removed and neutralised. Rome, Naples, and other destinations can learn from this, and avoid to reach a point of no return. From a systemic perspective, monetary flows activate (and are activated by) material and immaterial flows into and out of the system, but it is not always clear even in the public debate what the real goals of tourist transformations are. Being urban tourism an extractivist industry (Loperena, 2017; Salerno, 2018, 2018b), the goal of a tourist city is evidently profit maximisation for some. Thus, profit-seeking also represents the driver of urban transformations to receive tourists, and this does not automatically imply wellbeing for all. Reality may be very different.

Original sins, or the systemic flaws of attempted failing "solutions" to tourist issues in Venice. In the following, some recent proposals for supposedly handling overtourism are read through the systems diagram lens. First, the City of Venice experimented barriers to enter the two major itineraries to the main tourist attractions: visitors not staying in a registered hospitality facility or simply coming for a day trip would undergo a selection and a cap on entrance for expectedly overcrowded dates in 2018 and 2019. This was of course an attempt to act onto a portion of the information flowing outside the city so as to discourage daily excursions of potential unaware travellers: of course, a city cannot be "entered" just like a mediaeval fortress, so a way to reach their destination was anyway possible-but, in doubt, some might opt for postponing their visit. Anyway, data from section "Venice, Italy: an extreme yet not isolated case" show that only a minor portion of visitors is made of day trippers. Systemically speaking, this was an attempt to alter the information outflows or simply the internal consensus information flows, just to pretend to act. In the figure, this happens at the level of the bidirectional information flows in the top right part of the diagram. The city mayor himself soon declared the failure of such a tool. As also reported above (Salerno, 2018b; Dal Bianco, 2019), a tax on similar arrivals was already planned for 2021 before the abrupt drop in tourist presences. In addition to only targeting a negligible share of tourists, this was going to affect the lives of residents, having to pay up to $10 €$ a day per capita in order to host their friends and relatives at home, or just to have them entering the city to take part into even important events, ceremonies, or life occasions. With the excuse of supposedly tackling the overtourism issues, the expulsion of local population would be perpetrated by an additional tool. Both the selling off of public properties and the approval of changes in the urban plans to convert private and formerly public buildings into hotels ${ }^{22}$ confirm that the reduction of arrivals was not the real goal of such measures. On the contrary, this would be complying with the profit-maximisation goal of a tourist city, while appeasing complaints through vane or even worsening actions. Anyway, this is somewhat pertinent to any neoliberal policy of any urban or national government. From a systems perspective, a peculiar interesting behaviour can be observed, instead, in oppositional associations and movements. Some vaguely call for a "quality tourism", which is often translated into a tourism able to leave more money "to the city" (e.g. booking expensive accommodations, not bringing packed lunches, etc.). Again, although marginal in the light of the average composition of tourist flows, this might also be read as a mere class system proposal to preferentially welcome wealthier visitors, without really changing the self-destroying dynamics of the tourism phenomenon. This corresponds to empower the monetary flows, which anyway mostly flow out of the city, as seen in the description of the systems diagram. Some others mostly focus on cruise tourists, representing one-tenth of the arrivals but surely bringing severe social and ecological impacts. The main proposed options currently focus on two alternatives: (a) moving the cruise terminal to the industrial park of Porto Marghera, thus requiring megaprojects to build new structures and to dig new channels in highly contaminated lagoon floors, while mixing cruise ships with cargo and oil maritime transportation; and (b) moving it slightly out of the lagoon, thus requiring a brand-new offshore terminal, hordes of smaller pilot vessels to bring thousands of tourists to the old town, and attracting even larger cruise ships to Venice. Systemically speaking, none of them would result in a configuration change of the tourist city, yet they would both increase the problem by adding new inflows, as well as new risks (incidents, pollution, etc.). In the diagram, this is marked by an increase in the inflows coming from the tourists source through the transport services, and a corresponding increase in the waste produced by the tourist users' stock. Finally, some propose a cap on arrivals. It is not clear what the ideal cap would be nor how this would be managed if the goal and the configuration of the system are not questioned: there is a mismatch among limiting arrivals and enlarging the transport and accommodation capacity, which might either cause financial issues or-for the same reasonsmake any cap policy fail.

Learnings towards a rethinking of Venice and other overtourist destinations. To be effective, proposals would first require different priorities, goals, and structures to be set toward a different city, otherwise the systemic configuration will neutralise them. In other words, the question is not that of moving from a neoliberal approach back to some governmental control over a single economic sector (if systems are designed in a certain way, sooner or later they will adapt to restore their original function), but rather that of restarting the urban system from scratch. After the Covid19 pandemic, there is a general consensus inside and outside Venice that a significant change is required, that rethinking the city and its functions has become a must. At the first stages of the pandemic, an agreement was reached among the municipality, one of the local universities, and the association of tourist apartment owners in order to temporarily rent empty tourist apartments to students $^{23}$ for the next academic year after the global lockdown. It is beyond the purposes of the present work to analyse a measure like this, but it might be worth stressing that much more is required: if no rethinking is operated at a higher level, this initiative might just help those apartments become tourist accommodations again should the tourist demand be ever back as usual (another systemic re-adjustment). This study is, therefore, presented to support the aforementioned rethinking towards groundbreaking proposals arising from a brand-new goal for the city, while preventing new crises related to either overtourism or lack of tourism, and preserving the local quality of life, bringing residents back ${ }^{24}$. This should be accompanied by a careful look at the local hundreds-year-old sustainable traditions (such as slow paces, rowing boats, manifold kinds of artisanship, humanenvironment equilibria, etc.), and targeting the issue at an adequate level. Unfortunately, any other option, considering Russo's "vicious circle", would just mean to kill Venice as we know it, as a live, populated city-and, with similar approaches, also other tourist cities and destinations. In a capitalist economy there is no such a thing as a "good" or a "sustainable tourism". By means of a metaphor, it would like parasiting a victim until it dies or at least until it is no longer desirable or able to even survive by itself. 


\section{Conclusions}

In this paper, a conceptual description is provided for urban life, economy, and resilience in tourist cities and, more generally, destinations. In particular, Venice is addressed as a paradigmatic example where an intrinsic environmental fragility is being dramatically increased by the development of the tourism sector. The urban justice, resilience, and integrated sustainability issues related to tourism are addressed through systems thinking and diagramming. Our two-fold approach aims at both understanding the existing and prospective problems in the "regular" operations of a tourist city, and preventing further serious consequences in urban life and economy after major shocks such as that of the Covid-19 pandemic. Our study may be summarised as in the following:

- A novel systemic diagram of a tourist city is proposed as a potentially powerful underexploited epistemological tool to support the understanding of current urban transformations and of their dynamics. Systems thinking allows to make significant advances in the level of comprehension of the tourist issues, as well as in consequent counter-proposals in urban debates and planning to grant well-being, sustainability, and resilience. Besides laying the bases to rationally frame future quantitative analyses, a conceptual elaboration can suggest whether and to what extent such computations are required, in which crucial paths, or if other issues are to be discussed beforehand.

- The systemic goal of a city should be first of all the safety and well-being of its dwellers; anyway, being the urban tourism an extractivist industry framed in a capitalist economy, a tourist city seeks profit maximisation for the few, and traces of this real goal can be found in both problems and current actions passed off as solutions. Accordingly, job creation and capital attraction are part of a deceptive narrative: benefits (profits) mostly flow out of the destination, while regular and exceptional risks and impacts are borne by the whole city, including workers and small and medium enterprises. The social and ecological aspects of a poor sustainability are more evident, but the economic one is endangered as well.

- Two major leverage points are found: (a) the city's image, built up by its life and general economy, attracting tourists, and consequently being affected by touristification: this can ultimately become a self-destroying feedback, while depleting the city's culture, "authenticity", well-being, and resilience to external conditions; and (b) the competition between resident life and tourist industry for the allocation of the urban assets: such diversion of material and immaterial key stocks and flows from urban life and general economy to the tourist sector can be seen as an irreversible process. Based on the definition of sustainability and the current status of such leverage points, systemically speaking there cannot be such a thing as "sustainable tourism" in a capital accumulating society.

- Like purely ecological systems, a tourist monoculture is a weak and hardly resilient human-ecological system. Possible alternative strategies to improve overall conditions for urban life, economy, and shared well-being in tourist cities ought to pass through the rethinking of their systemic goals. Only from there can we proceed downstream with proposals and reconfigurations able to restore the cities' capabilities to get their livelihood independently of external driving forces, of which the Covid-19 pandemic is a recent but expectedly not isolated example in the twenty-first century. Systems teach us that all ages have a start and an end.

- From a systems perspective, all the measures publicly proposed by local institutions and main citizen groups to professedly tackle overtourism and the tourism drop in
Venice (respectively before or during the Covid-19 pandemic) seem to be either sharpening or at least not even minimally affecting these issues, inasmuch as inspired or simply conditioned by conflicting goals. Although often ineffective and still lacking a comprehensive view, if urban resistances and the institutional attempts to soothe them were at least nominally focused on overtourism, the pandemic suggests a need to rethink the entire city. From the conceptual elaboration to local implementability, a methodological path is here offered for a change to be lasting and to progressively pursue sustainable and just societies and economies out of the current Venetian recession.

\section{Data availability}

All data analysed or generated are included in the paper.

Received: 5 June 2020; Accepted: 21 October 2020;

Published online: 05 November 2020

\section{Notes}

1 Some of which have recently converged into an international network: SET-Southern European Cities against Touristification (Financial Tribune, 2018; Peeters et al., 2018), animated by grassroots groups from over 20 tourist destinations, mostly located in the Mediterranean area.

2 At the dawn of the phenomenon of modern mass tourism, it was reported that more tourism would mean more money (Nature, 1969); over fifty years later, we acknowledge that the issue is now much more complex than then.

3 It might be worth recalling that sustainability and resilience for urban transformations have been found to be sometimes in conflict (Elmqvist et al., 2019). This can be one reason more to comprehensively address such issues through systems thinking.

4 Through Stock-and-Flow Analysis, Soufivand (2012) focuses on the value co-creation aspect of some tourist services.

5 https://teatroitalia.despar.it/teatro-italia/.

6 https://www.comune.venezia.it/it/content/multisala-rossini.

7 https://www.dfs.com/it/venice/stores/t-fondaco-dei-tedeschi-by-dfs.

8 i.e., nearly $60 \%$ of resident population

9 For which, right before its outbreak, the world was declaredly unprepared (NTI, 2019; World Economic Forum, 2019).

10 At the beginning of the coronavirus emergency in Italy, tens of thousands of workers from the tourist sector were estimated to have already lost their salary in the sole metropolitan area of Venice (La Nuova di Venezia, 2020b).

11 Even the international channels of US-based media news CCN are reporting a wider perception that it would now be "time to rethink what Venice can be" (Nadeau, 2020).

12 See for instance d'Eramo (2019).

13 Some further correlations of housing use and tourism rates (see Bourne, 2019) with rising prices in Venice might also affect refurnishment and, therefore, indirectly ease conversion of regular apartments into tourist apartments; although this aspect does not represent the core of our study, it can be seen as part of the listed direct and indirect effects.

14 See for instance Naidoo et al. (2016).

15 In addition to floods risk, iconic in Venice but also valid throughout the world (see Jongman, 2018), Icelandic eruptions also represent globally renown events (see Bird and Gísladóttir, 2018).

16 Whose effects on tourism have been recently analysed by Eyre et al. (2020).

17 See for instance Amsterdam and its coffee shops (Taylor, 2019).

18 Leigh (2020) and many others talk about the second highest tide ever after 1966, but they refer to the tide rise above average sea level, which has also risen in the meantime (see Camuffo et al., 2017).

19 https://www.comune.venezia.it/it/content/buoni-spesa-informazioni-utili (Accessed May 2020).

20 https://www.ilgazzettino.it/nordest/venezia/coronavirus_spesa_sospesa_venezia5203454.html (Accessed May 2020).

21 Even amid the pandemic, tourism is emblematically expected to help "improve our lives" (D'Adamo and Rosa, 2020).

22 The most recent of which-the emblematic conversion of a hospital into a tourist resort-officialised right during Covid-19 pandemic crisis (https://www. metropolitano.it/lido-ospedale-centro-turistico/, Accessed May 2020).

$23 \mathrm{https} / / /$ live.comune.venezia.it/it/protocollo-intesa-iuav-comune-locazioni. 
$24 \mathrm{https} / /$ www.internazionale.it/reportage/francesco-erbani/2020/05/14/centri-storiciairbnb (Accessed May 2020).

\section{References}

Agamben G (2003) Stato di eccezione. Bollati Boringhieri, Torino

Alcott B, Giampietro M, Mayumi K, Polimeni J (2012) The Jevons paradox and the myth of resource efficiency improvements. Routledge

Andriotis K (2018) Degrowth in tourism: conceptual, theoretical and philosophical issues. $\mathrm{CABI}$

Architonic (2019). Studio Architetto Mar. Nuova Aerostazione Passeggeri dell'Aeroporto Marco Polo, Tessera, Venezia, Italia, 2002 [https://www. architonic.com/it/project/studio-architetto-mar-nuova-aerostazionepasseggeri-dellaeroporto-marco-polo/5100588, Accessed May 2020]

Ballé M (1994) Managing with systems thinking: making dynamics work for you in business decision making. McGraw-Hill International (UK)

Beech JG, Beech J, Chadwick S (eds.) (2006) The business of tourism management. Pearson education

Bellinger G (2004) Translating systems thinking diagrams to stock \& flow diagrams, http://www.systems-thinking.org/stsf/stsf.htm (Accessed May 2020)

Bertocchi D, Camatti N, Giove S, van der Borg J (2020) Venice and overtourism: simulating sustainable development scenarios through a tourism carrying capacity model. Sustainability 12(2):512

Bertocchi D, Visentin F (2019) "The Overwhelmed City": physical and social overcapacities of global tourism in Venice. Sustainability 11(24):6937

Bird DK, Gísladóttir G (2018) Responding to volcanic eruptions in Iceland: from the small to the catastrophic. Palgrave Commun 4:151. https://doi.org/ 10.1057/s41599-018-0205-6

Boardman J, Sauser B (2008) Systems thinking: coping with 21st century problems. CRC Press

Borrelli C (2018) La Vida a Venezia: anatomia di una città. Il lavoro culturale. [http://www.lavoroculturale.org/venezia-la-vida/, Accessed Dec 2019]

Bossel H (2007) Systems and models: complexity, dynamics, evolution, sustainability. Books on Demand, Germany

Bourne J (2019) Empty homes: mapping the extent and value of low-use domestic property in England and Wales. Palgrave Commun 5(1):1-14

Butler RW (1999) Sustainable tourism: a state-of-the-art review. Tour Geogr 1 (1):7-25

Calzada I (2020) Seeing tourism transformations in Europe through algorithmic techno-political and city-regional lenses. In: Coppieters and Ezkerraberri Foundations (eds) 2020/01. Transforming tourism: regional perspectives on a global phenomenon. Ch. 6. Centre Maurits Coppieters CMC, Brussels, pp. 74-89. ISBN: 978-90-826321-0-1

Camisani PB (2018) Sri Lanka: a political ecology of socio-environmental conflicts and development projects. Sustain Sci 13:693-707. https://doi.org/10.1007/ s11625-018-0544-7

Camuffo D, Bertolin C, Schenal P (2017) A novel proxy and the sea level rise in Venice, Italy, from 1350 to 2014. Clim Change 143(3):1-14

Capra F (1985) Criteria of systems thinking. Futures 17(5):475-478

Carballo RR, León CJ, Carballo MM (2019) Fighting overtourism in Lanzarote (Spain). Worldwide Hospitality and Tourism Themes

Casert R (2020) Venice Mayor Says City 'Is on Its Knees' as Coronavirus Decimates European Tourism. Time [https://time.com/5824905/european-tourismcoronavirus/, Accessed Apr 2020]

Cassinger C, Månsson M (2019) Mass tourism at a tipping point: exploring the mediatisation of overtourism. In: 28th Nordic Symposium on Tourism and Hospitality Research, Roskilde, Denmark

Checkland P (1981) Systems thinking, systems practice. John Wiley \& Sons, New York

Città di Venezia-Assessorato al Turismo (2018) Annuario del Turismo, dati 2017 Città di Venezia-Servizio Statistica e Ricerca (2020) Popolazione: dati e studi

Comune di Venezia (2019) Contributo di accesso a Venezia: presentata dal sindaco Brugnaro la proposta di regolamento: "Via dall'1 maggio" [https://live. comune.venezia.it/it/contributo-accesso-sbarco-venezia-come-funziona, Accessed Apr 2020]

Cristiano S (2018) Systemic thoughts on ecology, society, and labour. In: Cristiano $S$ (ed.) Through the working class ecologyand society investigated through the lens of labour. Ca' Foscari University Press, Venice, Italy, pp. 9-23

Cristiano S (2019) Cosa si fa di una città? Il caso de La Vida di Venezia. Granello di Sabbia, 40

Cristiano S, Zucaro A, Liu G, Ulgiati, S, Gonella F (2020) On the systemic features of urban systems. A look at material flows and cultural dimensions to address post-growth resilience and sustainability. Front Sustain Cities 12, (2). https:// doi.org/10.3389/frsc. 2020.00012

D'Adamo I, Rosa P (2020) How do you see infrastructure? green energy to provide economic growth after COVID-19. Sustainability 12:4738

Dal Bianco E (2019) Monitoraggio dei flussi turistici urbami: caso studio Venezia. MSc thesis in Governance of Public Organisations. Università Ca' Foscari Venezia, 116
Debord G (1967) La Societé du Spectacle. Buchet/Chastel, Paris

d'Eramo M (2019) Il selfie del mondo: indagine sull'età del turismo. Feltrinelli Editore

Dodds R, Butler R (eds.) (2019) Overtourism: issues, realities and solutions (vol. 1). De Gruyter Oldenbourg

Duan H, Wang S, Yang C (2020) Coronavirus: limit short-term economic damage. Nature 578(7796):515

Elmqvist T, Andersson E, Frantzeskaki N, McPhearson T, Olsson P, Gaffney O, Folke C (2019) Sustainability and resilience for transformation in the urban century. Nat Sustain 2(4):267-273

Engelman R (2013) Beyond sustainable. In: State of the World 2013. Island Press/ Center for Resource Economics. pp. 3-16

Eyre R, De Luca F, Simini F (2020) Social media usage reveals recovery of small businesses after natural hazard events. Natu Commun 11:1629. https://doi. org/10.1038/s41467-020-15405-7

Farrell B, Twining-Ward L (2005) Seven steps towards sustainability: tourism in the context of new knowledge. J Sustain Tour 13(2):109-122

Fernandes N (2020) Economic effects of coronavirus outbreak (COVID-19) on the world economy. SSRN: https://doi.org/10.2139/ssrn.3557504

Financial Tribune (2018) South Europe cities rise against mass tourism [https:// financialtribune.com/articles/travel/85379/south-europe-cities-rise-againstmass-tourism]

Fletcher R, Murray Mas I, Blanco-Romero A, Blázquez-Salom M (2019) Tourism and degrowth: an emerging agenda for research and praxis. J Sustain Tour 27 (12):1745-1763

Foramitti J, Varvarousis A, Kallis G (2020) Transition within a transition: how cooperative platforms want to change the sharing economy. Sustain Sci https://doi.org/10.1007/s11625-020-00804-y

Force A, Manuel-Navarrete D, Benessaiah K (2018) Tourism and transitions toward sustainability: developing tourists' pro-sustainability agency. Sustain Sci 13:431-445. https://doi.org/10.1007/s11625-017-0448-y

Forrester JW (1973) Principles of systems: text and workbook. MIT Press, Cambridge, MA

García-Hernández M, la Calle-Vaquero D, Yubero C (2017) Cultural heritage and urban tourism: historic city centres under pressure. Sustainability 9(8):1346

Gonella F (2019) The smart narrative of a smart city. Front Sustain Cities 1:9

Gonella F, Casazza M, Cristiano S, Romano A (2020) Addressing COVID-19 communication and management by a systems thinking approach. Front Commun 5:63

Haines S (2016) The systems thinking approach to strategic planning and management. CRC Press

Haldane A (2020) To set coronavirus policy, model lives and livelihood in lockstep. Nature 571:357

Haldane A, May M (2011) Systemic risk in banking ecosystems. Nature 469:351-355

Higgins-Desbiolles F (2020) Socialising tourism for social and ecological justice after COVID-19. Tour Geogr 22(3):610-623

Higgins-Desbiolles F, Carnicelli S, Krolikowski C, Wijesinghe G, Boluk K (2019) Degrowing tourism: rethinking tourism. J Sustain Tour 27(12):1926-1944

Holling CS (1973) Resilience and stability of ecological systems. Ann Rev Ecol System 4(1):1-23

Honjo K, Kubo T (2020) Social dilemmas in nature-based tourism depend on social value orientations. Sci Rep 10(1):1-10

Hotel Domani (2018) Rosewood Hotels approda a Venezia con una nuova apertura nel 2020. November 6, 2018. [https://www.hoteldomani.it/rosewood-hotels approda-a-venezia-nel-2020/, Accessed May 2020]

Iacus SM, Natale F, Vespe M (2020) Flight restrictions from China during the COVID-2019 Coronavirus outbreak. arXiv preprint arXiv:2003.03686

ICOSMOS Documentation Centre. (2017). Sustainable Tourism

Il Gazzettino (2019) Inaugurati 4 nuovi hotel. E ne spunta già un altro. June 21 [https://www.ilgazzettino.it/nordest/venezia/mestre_hotel_venezia-4571350. html, Accessed May 2020]

Il Gazzettino (2020) Nuovo hotel "dentro" gli ex gasometri, l'imprenditore: «Progetto utile alla città». Jan 18. [https://www.ilgazzettino.it/nordest/venezia/ ex_gasometri_hotel_san_francesco_vigna-4990067.html, Accessed Mar 2020]

Ioannides D, Leventis P, Petridou E (2016) Urban resistance tourism initiatives in stressed cities: the case of Athens. In: Russo A, Richards G. (eds.) Reinventing the Local in Tourism: Producing, Consuming, and Negotiating Place. Channel View Publications, Bristol, p. 229-250

Jakulin TJ (2017) Systems approach to tourism: a methodology for defining complex tourism system. Organizacija 50(3):208-215

Jevons WS (1865) The coal question: an inquiry concerning the progress of the nation, and the probable exhaustion of the coal-mines. Macmillan, London

Jongman B (2018) Effective adaptation to rising flood risk. Nat Commun 9:1986 https://doi.org/10.1038/s41467-018-04396-1

Jover J, Díaz-Parra I (2019) Gentrification, transnational gentrification and touristification in Seville, Spain. Urban Studies, 0042098019857585 
Kerr T, Wardana A (2019) Utopian resort living: islands of reclamation and environmental resistance in Bali and Western Australia. J Tour Cult Chang 1-14. https://doi.org/10.1080/14766825.2019.1694534

La Nuova di Venezia (2020a) Venezia, nuovo albergo aperto ieri all'interno di Palazzo Pemma. Feb 7, 2020 [https://nuovavenezia.gelocalit/venezia/ cronaca/2020/02/08/news/nuovo-albergo-aperto-ieri-all-interno-di-palazzopemma-1.38439297, Accessed Feb 2020]

La Nuova di Venezia (2020b) Stagione turistica semi azzerata. Nel Veneziano 50 mila lavoratori senza reddito. March 31 [https://nuovavenezia.gelocal.it/ venezia/cronaca/2020/04/01/news/stagione-turistica-semi-azzerata-50-milalavoratori-senza-un-reddito-1.38662114, Accessed Apr 2020]

La Repubblica (2019) Venezia, l'acqua alta di novembre si è portata via i turisti: "Perdiamo 10 milioni di euro al giorno". Dec 30, 2019 [https://video.repubblica.it/ cronaca/venezia-l-acqua-alta-di-novembre-si-e-portata-via-i-turisti-perdiamo-10milioni-di-euro-al-giorno/351126/351699, Accessed Apr 2020]

Lazanski TJ, Kljajic M (2006) Systems approach to complex systems modelling with special regards to tourism. Kybernetes 35(7-8):1048-1058

Lebe SS, Wang ZX, Pei L (2014) A systems thinking-based grey model for sustainability evaluation of urban tourism. Kybernetes 43(3/4):462-479

Leigh C (2020) Venice afloat. first things: a monthly. J Relig Public Life 301:13-17

Lenzen M, Sun Y, Faturay F, Ting Y, Geschke A, Malik A (2018) The carbon footprint of global tourism. Nat Clim Chang 8:522-528. https://doi.org/ 10.1038/s41558-018-0141-x

Leposa, N. (2020) Problematic blue growth: a thematic synthesis of social sustainability problems related to growth in the marine and coastal tourism. Sustain Sci. https://doi.org/10.1007/s11625-020-00796-9

Lin BB (2011) Resilience in agriculture through crop diversification: adaptive management for environmental change. BioScience 61(3):183-193

Loperena CA (2017) Honduras is open for business: extractivist tourism as sustainable development in the wake of disaster? J Sustain Tour 25(5):618-633

Luna-Reyes LF, Andersen DL (2003) Collecting and analyzing qualitative data for system dynamics: methods and models. System Dynam Rev 19(4):271-296

Maani KE, Cavana RY (2007) Systems thinking, system dynamic: managing change and complexity, 2nd edn. Pearson, Prentice Hall

Mai T, Smith C (2015) Addressing the threats to tourism sustainability using systems thinking: a case study of Cat Ba Island, Vietnam. J Sustain Tour 23 (10):1504-1528

Meadows DH (1999) Leverage points: places to intervene in a system. The Sustainability Institute

Meadows DH (2008) Thinking in systems: a primer. Chelsea Green Publishing

Milano C, Novelli M, Cheer JM, Blanco-Romero A, Blázquez-Salom M, Bakker M, Okada M (2019) Overtourism: a critical state of the art. Crit Tour Stud Proc 2019:1. Available at https://digitalcommons.library.tru.ca/cts-proceedings/ vol2019/iss1/1

Moslem S, Campisi T, Szmelter-Jarosz A, Duleba S, Nahiduzzaman KM, Tesoriere G (2020) Best-worst method for modelling mobility choice after COVID-19: evidence from Italy. Sustainability 12(17):6824

Nadeau, BN (2020) Deserted Venice contemplates a future without tourist hordes after Covid-19. CNN Travel, May 16, 2020 [https://edition.cnn.com/travel/ article/venice-future-covid-19/index.html, Accessed May 2020]

Naidoo R, Fisher B, Manica A, Balmford A (2016) Estimating economic losses to tourism in Africa from the illegal killing of elephants. Nat Commun 7(1):1-9

Nature (1969) Tourism: more people, more money. Nature 223:994. https://doi. org/10.1038/223994a0

Navarro-Jurado E, Romero-Padilla Y, Romero-Martínez JM, Serrano-Muñoz E, Habegger S, Mora-Esteban R (2019) Growth machines and social movements in mature tourist destinations Costa del Sol-Málaga. J Sustain Tour 27 (12):1786-1803

Nepal R, Nepal SK (2019) Managing overtourism through economic taxation: policy lessons from five countries. Tour Geogr, 1-22. https://doi.org/10.1080/ 14616688.2019 .1669070

Nguyen NC, Bosch OJ (2013) A systems thinking approach to identify leverage points for sustainability: a case study in the Cat Ba Biosphere Reserve, Vietnam. System Res Behav Sci 30(2):104-115

Norman B (2018) Are autonomous cities our urban future? Nat Commun 9:2111. https://doi.org/10.1038/s41467-018-04505-0

NTI (Nuclear Threat Initiative) (2019) "Global Health Security Index: Inaugural Global Health Security Index finds no country is prepared for epidemics or pandemics". NTI. Press Release, 24 Oct 2019. [https://www.nti.org/ newsroom/news/inaugural-global-health-security-index-finds-no-countryprepared-epidemics-or-pandemics/, Accessed Apr 2020]

Oklevik O, Gössling S, Hall CM, Steen Jacobsen JK, Grøtte IP, McCabe S (2019) Overtourism, optimisation, and destination performance indicators: a case study of activities in Fjord Norway. J Sustain Tour 27(12):1804-1824

Odum HT (1983) Systems ecology; an introduction. Wiley

Odum HT (1994) Ecological and general systems: an introduction to systems ecology. University Press of Colorado, Niwot, CO
Odum HT (2007) Environment, power, and society for the twenty-first century: the hierarchy of energy. Columbia University Press

Odum HT, Odum EC (2008) A prosperous way down: principles and policies. University Press of Colorado

Perkumienè D, Pranskūnienè R (2019) Overtourism: between the right to travel and residents' rights. Sustainability 11(7):2138

Peeters PM, Gössling S, Klijs J, Milano C, Novelli M, Dijkmans CHS, Mitas O (2018) Research for TRAN Committee-Overtourism: impact and possible policy responses. European Parliament, Directorate General for Internal Policies, Policy Department B: Structural and Cohesion Policies, Transport and Tourism

Pollock K (2016) Urban physics. Nat 531:S64-S66. https://doi.org/10.1038/531S64a Porto di Venezia (2019) Passeggeri. 2018 [https://www.port.venice.it/it/passeggeri. html, Accessed May 2020]

Postma A, Buda DM, Gugerell K (2017) The future of city tourism. J Tour Future 3 (2):95-101

RAI-Radiotelevisione Italiana (2019) Dopo l'acqua alta, la fuga dei turisti. A Venezia $40 \%$ di arrivi in meno. TGR, Dec 7, 2019. [https://www.rainews.it/ tgr/veneto/video/2019/12/ven-Venezia-acqua-alta-turismo-calo-albergatorieb66bad9-da7b-4eb5-a209-742ca17e44b4.html, Accessed Apr 2020]

Reimann L, Vafeidis AT, Brown S, Hinkel J, Tol SJ (2018) Mediterranean UNESCO World Heritage at risk from coastal flooding and erosion due to sea-level rise. Nat Commun 9:4161. https://doi.org/10.1038/s41467-018-06645-9

Roxas FMY, Rivera JPR, Gutierrez ELM (2020) Framework for creating sustainable tourism using systems thinking. Curr Issue in Tour 23(3):280-296

Russo AP (2002) The "vicious circle" of tourism development in heritage cities. Ann Tour Res 29(1):165-182

Salerno GM (2018) Estrattivismo contro il comune. Venezia e l'economia turistica. ACME 17(2):480-505

Salerno GM (2018) Industria turistica e patrimonio: un dispositivo estrattivo alla luce del "modello Civita". Territorio 86:39-47

Sanchez AX, Van der Heijden J, Osmond P (2018) The city politics of an urban age: urban resilience conceptualisations and policies. Palgrave Commun 4(1):1-12

Schianetz K, Kavanagh L (2008) Sustainability indicators for tourism destinations: a complex adaptive systems approach using systemic indicator systems. J Sustain Tour 16(6):601-628

Schiermeier Q (2004) Ecologists mount protest over lofty plans for Alpine ski runs. Nature 431:235-236

Scott JC (1998) Seeing like a state: how certain schemes to improve the human condition have failed. Yale University Press

Soufivand M (2012) Enhancement of tourism service delivery performance through value co-creation: a system dynamic approach: case Study: Cultural heritage sector in Sicily. MSc thesis in Production Engineering and Management. KTH Royal Institute of Technology

Seraphin H, Sheeran P, Pilato M (2018) Over-tourism and the fall of Venice as a destination. J Dest Mark Manage 9:374-376

Shoval N (2018) Urban planning and tourism in European cities. Tour Geogr 20 (3):371-376

Smith MK, Sziva IP, Olt G (2019) Overtourism and resident resistance in Budapest. Tour Plan Dev 16(4):376-392

Stanley JL (2020) Revising Reykjavík: changing narratives of skeletons, structures, and imagined futures. Sustain Sci. https://doi.org/10.1007/s11625-020-00817-7

Sterman JD (1994) Learning in and about complex systems. Syst Dyn Rev 10(23):291-330

Sterman JD (2012) Sustaining sustainability: creating a systems science in a fragmented academy and polarized world. In Sustainability science. Springer, New York, NY, pp. 21-58

Taylor LL (2019) Defining marijuana tourism. J Hosp Tour Res 43(3):438-446

Tembo D (2020) The road now less travelled. In: International Trade Forum (No. 1, pp. 3-3). International Trade Centre

UNEP-United Nations Environmental Programme (2005) Making tourism more sustainable: a guide for policy makers. United Nations Environment Programme, Division of Technology, Industry and Economics, Paris

UNESCO (2015) World Heritage Committee. Decision: 38 COM 7B.27 Venice and its lagoon (Italy) (C 394)

UNESCO (2019) UNESCO closely monitoring ongoing threats to Venice World Heritage Site [https://whc.unesco.org/en/news/2043, Accessed May 2020]

UNWTO-World Tourism Organisation (1993) Sustainable tourism development: Guide for local planners. Madrid

UNWTO-World Tourism Organisation (2020) Sustainable tourism development [https://www.unwto.org/sustainable-development, Accessed Apr 2020]

Valdivielso J, Moranta J (2019) The social construction of the tourism degrowth discourse in the Balearic Islands. J Sustain Tour 27(12):1876-1892

Van Mai T (2010) Systems thinking approach as a unique tool for sustainable tourism development: a case study in the cat ba biosphere reserve of Vietnam. In: Proceedings of the 54th Annual Meeting of the ISSS-2010, Waterloo, Canada (vol. 54, No. 1 ) 
Venezia Airport (2019) Statistiche e traffico. I dati annuali su passeggeri, merci e movimenti dei voli dell'Aeroporto Marco Polo di Venezia

von Bertalanffy L (1968) General system theory: foundations, development, applications. George Braziller, New York, NY

Walker PA, Greiner R, McDonald D, Lyne V (1998) The tourism futures simulator: a systems thinking approach. Environ Model Softw 14(1):59-67

Winengan W (2019) Local community resistance in Lombok against tourism development policy. Masyarakat, Kebudayaan dan Politik 32(1):69-79

World Economic Forum (2019) Global risk report 2020 [https://www.weforum. org/reports/the-global-risks-report-2020, Accessed Apr 2020]

Xue J, Liu G, Casazza M, Ulgiati S (2018) Development of an urban FEW nexus online analyzer to support urban circular economy strategy planning. Energy 164:475-495

Zanardi C (2020) Oltre la monocultura turistica. Verso un altro ordine del discorso. Conference paper. Convegno 'Oltre la monocultura del turismo. Per un atlante delle resistenze e delle contro-progettualità'. Università degli Studi di Roma 'La Sapienza', Rome, Italy, Jun 11, 2019

\section{Acknowledgements}

This work is partly supported by the Italian Ministry of Foreign Affairs and International Cooperation, Direzione Generale per la Promozione del Sistema Paese (MAECI, High Relevance Bilateral Projects, grant code PGR05278).

\section{Author contributions}

Concept and overall elaboration by SC. Revision and amendments by FG. FG's long-term inspiration and past supervision play here an indirect yet highly valuable role. Both authors contributed to the article and approved the submitted version.

\section{Competing interests}

The authors declare no competing interests.

\section{Additional information}

Correspondence and requests for materials should be addressed to S.C.

Reprints and permission information is available at http://www.nature.com/reprints

Publisher's note Springer Nature remains neutral with regard to jurisdictional claims in published maps and institutional affiliations.

\begin{abstract}
(c) (i) Open Access This article is licensed under a Creative Commons Attribution 4.0 International License, which permits use, sharing, adaptation, distribution and reproduction in any medium or format, as long as you give appropriate credit to the original author(s) and the source, provide a link to the Creative Commons license, and indicate if changes were made. The images or other third party material in this article are included in the article's Creative Commons license, unless indicated otherwise in a credit line to the material. If material is not included in the article's Creative Commons license and your intended use is not permitted by statutory regulation or exceeds the permitted use, you will need to obtain permission directly from the copyright holder. To view a copy of this license, visit http://creativecommons.org/ licenses/by/4.0/.
\end{abstract}

(C) The Author(s) 2020 